\title{
Cd4+ T-cell-dependent Goblet Cell Proliferation and Expulsion of Gymnophalloides seoi from the Intestine of $\mathrm{C} 57 \mathrm{bl} / 6$ Mice
}

\author{
Author(s) :Sang-Mee Guk, Jun-Haeng Lee, Hyo-Jin Kim, Won-Hee Kim, Eun-Hee Shin, and Jong-Yil
} Chai

Source: Journal of Parasitology, 95(3):581-590. 2009.

Published By: American Society of Parasitologists

DOI: http://dx.doi.org/10.1645/GE-1807.1

URL: http://www.bioone.org/doi/full/10.1645/GE-1807.1

BioOne (www.bioone.org) is a nonprofit, online aggregation of core research in the biological, ecological, and environmental sciences. BioOne provides a sustainable online platform for over 170 journals and books published by nonprofit societies, associations, museums, institutions, and presses.

Your use of this PDF, the BioOne Web site, and all posted and associated content indicates your acceptance of BioOne's Terms of Use, available at www.bioone.org/page/terms_of_use.

Usage of BioOne content is strictly limited to personal, educational, and non-commercial use. Commercial inquiries or rights and permissions requests should be directed to the individual publisher as copyright holder. 


\title{
CD4+ T-CELL-DEPENDENT GOBLET CELL PROLIFERATION AND EXPULSION OF GYMNOPHALLOIDES SEOI FROM THE INTESTINE OF C57BL/6 MICE
}

\author{
Sang-Mee Guk, Jun-Haeng Lee ${ }^{\star}$, Hyo-Jin Kim†, Won-Hee Kim†, Eun-Hee Shin†‡, and Jong-Yil Chai†§ \\ Department of Parasitology, Korea University College of Medicine, Seoul 136-705, Korea. e-mail: cjy@snu.ac.kr
}

\begin{abstract}
Mechanisms for the spontaneous worm expulsion from the host intestine are not well understood in gastrointestinal trematode models. We studied the role of CD4+ T-helper cells in mediating goblet cell hyperplasia and expulsion of Gymnophalloides seoi from the intestines of C57BL/6 (resistant) and ICR (susceptible) mice. C57BL/6 mice expelled all G. seoi worms within 4 days post-infection (PI), while ICR mice did not completely expel worms until day 7 PI. This difference in worm expulsion was associated with high numbers of mucosal goblet cells in C57BL/6 mice along with alteration of the mucin quality, with changes in the terminal sugar chain and high levels of IL-4 and IL-5 mRNA expression in mesenteric lymph nodes. Adoptive transfer of mucosal CD4+ T-helper cells to syngeneic mice elicited strong goblet cell hyperplasia and a notably accelerated worm expulsion. However, this T-helper cell transfer had no relationship with the alteration of mucin quality. The results showed that CD4+ T-helper cells play an important role as a mediator of goblet cell hyperplasia, but not for functional activation of goblet cells. It is suggested that both T-cell dependent and independent mechanisms operate for expulsion of $G$. seoi from the mouse intestine.
\end{abstract}

Many gastrointestinal helminths, including nematodes, trematodes, and cestodes, are spontaneously expelled from the host within a few days to a week after a primary infection. Commonly studied nematode and cestode models include Trichinella spiralis, Nippostrongylus brasiliensis, Heligmosomoides polygyrus, Strongyloides spp., Trichuris suis, and Hymenolepis diminuta (Ishikawa et al., 1997; Dehlawi et al., 2006; Kringel et al., 2006; Webb et al., 2007). Trematode study models include Echinostoma trivolvis, E. caproni, E. hortense, Neodiplostomun seoulense, Metagonimus yokogawai, and Gymnophalloides seoi. These trematodes were found to be spontaneously expelled from rodent intestines after days 3-21 post-infection (PI) (Fujino et al., 1996; Chai et al., 1998; Seo et al., 2003; Guk et al., 2005; Cho et al., 2007).

T-helper-2 (Th2)-type host immune responses are important in worm expulsion in nematode models, and major effector cells in this paradigm include mucosal mast cells and goblet cells (GCs) (Kawai et al., 2007; Humphreys et al., 2008). The relative importance of mast cells and GCs varies by different species of worms. For example, GCs are important in the expulsion of $N$. brasiliensis, whereas mast cells are crucial in the expulsion of Strongyloides ratti (Else and Finkelman, 1998; Onah and Nawa, 2000). Both GCs and mast cells are involved in the expulsion of $T$. spiralis and H. polygyrus (Else and Finkelman, 1998). In trematode and cestode models such as $E$. caproni, E. trivolvis, $G$. seoi, and $H$. diminuta, worm expulsion is based on GCs alone as the most important effector cell population (Fujino et al., 1996; Seo et al., 2003; Toledo et al., 2006; Webb et al., 2007).

T-cell dependent quantitative changes in GCs and qualitative

Received 31 July 2008; revised 1 November 2008; accepted 5 November 2008.

* Division of Gastroenterology, Sungkyunkwan University College of Medicine and Samsung Medical Center, Seoul 135-710, Korea.

$\dagger$ Department of Parasitology and Tropical Medicine, Seoul National University College of Medicine, and Institute of Endemic Diseases, Seoul National University Medical Research Center, Seoul 110-799, Korea.

$\ddagger$ Seoul National University Bundang Hospital, Gyeonggi-do 463-707, Korea.

$\S$ To whom correspondence should be addressed.

DOI: $10.1645 / G E-1807.1$ changes in the terminal sugar of mucins secreted from GCs have been suggested to significantly influence worm expulsion of $N$. brasiliensis from infected rodents (Ishikawa et al., 1993; Onah and Nawa, 2000). However, T-cell independent GC hyperplasia and mucin production were also shown in athymic rats infected with $N$. brasiliensis (Kawai et al., 2007). Therefore, the mechanisms of GC hyperplasia and mucin production in response to nematode infections appear to be complex. The role of T-cells on GC hyperplasia and mucin production in trematode infections is poorly known.

In the Republic of Korea, G. seoi (Digenea: Gymnophallidae) is a human intestinal trematode transmitted by oysters (Lee and Chai, 2001; Chai et al., 2003; Shin et al., 2008). It is expelled from the intestines of experimentally infected mice within 3-14 days PI (Lee and Chai, 2001; Seo et al., 2003). C57BL/6 mice exhibit resistance to infection, and worms are expelled within 3 days. Conversely, ICR and $\mathrm{C} 3 \mathrm{H} / \mathrm{HeN}$ mice are susceptible to infection, and worms stay for a longer period of time (Lee et al., 1997). The expulsion of G. seoi was shown to be related to strong GC hyperplasia and delayed worm expulsion, together with suppressed GC hyperplasia, as was observed in immunosuppressed C57BL/6 mice (Seo et al., 2003).

We examined the importance of mucosal CD4+ T-cells in the regulation of GC hyperplasia, in the alteration of terminal sugar residue on GC mucins, and in worm expulsion of G. seoi from mice. We used resistant (C57BL/6) and susceptible (ICR) mouse strains to evaluate the dynamics of infection. In addition, we observed the effects of an adoptive transfer of mucosal CD4+ T-cells and the associated roles of Th2 cytokines such as IL-4 and IL-5 on GC hyperplasia, GC activation, and worm expulsion in recipient mice.

\section{MATERIALS AND METHODS}

\section{Animals and experimental infection with metacercariae}

Specific pathogen-free C57BL/6 (resistant) and ICR (susceptible) mice were purchased from an animal center (Samtako, Osan, Republic of Korea). Donor mice were used for CD4+ T-cells and each mouse strain consisted of 10-15 males per group; mice were 4-wk-old and 20$25 \mathrm{~g}$ in body weight. Each strain had 5 recipient male mice per group. Mice were supplied with food and water sterilized by irradiation and autoclaving. At predetermined days, mice were killed by cervical dislocation. Animal experiments were carried out in accordance with the 
guidelines of Institutional Animal Care and User Committee, Seoul National University College of Medicine, Seoul, Korea.

Naturally infected oysters, Crassostrea gigas, were collected from Shinan-gun, Jeollanam-do, which is an area endemic for gymnophalloidiasis in the Republic of Korea (Lee et al., 1994). The oyster shells were removed and the animal parts were digested in artificial digestive juice $(0.5 \%$ pepsin $1: 10,000$ in $0.6 \% \mathrm{HCl}$ solution; Sigma, St. Louis, Missouri) at $37 \mathrm{C}$ for $3 \mathrm{~min}$. The digested material contained free metacercariae and was washed several times with normal physiological saline. Metacercariae were collected using a stereomicroscope (SZ 3060, Olympus, Tokyo, Japan) after repeated sedimentation and washing. Two hundred metacercariae were administered orally per mouse.

\section{Adoptive transfer of mucosal CD4+ T-cells}

Mesenteric lymph nodes (MLNs) were obtained on days 0, 2, and 7 PI. The MLNs were trimmed of fat and cut into small pieces with scissors. Single-cell MLN suspensions were made by pressing pieces through a stainless steel mesh into RPMI 1640 media (Gibco BRL, Grand Island, New York), supplemented with $10 \%$ fetal bovine serum (FBS, Gibco BRL), and filtered through a nylon membrane to exclude dead cells and debris. The cell suspension was washed 3 times with $10 \%$ FBS/RPMI-1640.

The MLN cells were separated into CD4+ and CD4- populations prior to intravenous transfer into recipient mice. The separation was performed using anti-mouse CD4 antibody bound to magnetic beads and a magnetic cell-sorting system (MACS) (Miltenyl Biotech, Bergisch, Gladbach, Germany) according to the manufacturer's instructions. Isolated cells were stained with anti-mouse CD4 phycoerythrin (IgG2b, PharMingen, San Diego, California) and assayed with a fluorescenceactivated cell sorter (FACScan) (Becton Dickinson, Sparks, Maryland) to confirm the purity. The proportion (by percentage) of cells expressing certain molecules was confirmed as being more than $93 \%$ at each time.

CD4+ T-cells or CD4- T-cells were resuspended at a concentration of $10^{6}$ cells/100 $\mu \mathrm{l}$. Syngeneic recipient C57BL/6 and ICR mice were injected intravenously with $10^{6}$ cells per mouse at $24 \mathrm{hr}$ prior to oral challenge with $200 \mathrm{G}$. seoi metacercariae. The recipient mice were killed on day 1,2 , or 3 PI (C57BL/6) or on day 2 , 4, or 7 PI (ICR). Timing of host death was based on active periods of worm expulsion from mice infected with G. seoi. Experimental groups were divided into normal infected mice, recipient mice adoptively transferred with CD4+ T-cells purified from uninfected donor mice $\left(\mathrm{R}_{\text {nor }}\right)$, or from infected donor mice on days $2\left(\mathrm{R}_{\mathrm{d} 2 \mathrm{~d}}\right)$ and $7\left(\mathrm{R}_{\mathrm{d} 7 \mathrm{~d}}\right) \mathrm{PI}$.

\section{Worm recovery}

Mice in each group were killed by cervical dislocation, and larval and adult flukes were recovered using the Baermann's apparatus (Beaver et al., 1984). The flukes were collected from the bottom of the tube equipped in the apparatus. Intestinal segments were returned to Petri dishes to search for residual flukes under stereomicroscopy.

\section{Histology}

The middle portion of the jejunum was fixed in Carnoy's fixative for 4-6 hr for the detection of intestinal GCs. Fixed tissues were embedded in paraffin and sectioned at a $4-\mu \mathrm{m}$ thickness. Intestinal tissue samples were stained with periodic acid Schiff (PAS) solution and GCs were counted per 10 villus-crypt unit (VCU). Lectin histochemistry was performed in order to detect altered GC mucins using Helix pomatia agglutinin (HPA), which specifically recognizes the terminal GalNAc residues on the altered GC mucins (Ishikawa, 1994; Ishikawa et al., 1994) The procedure described by Ishikawa et al. (1994) was followed. The values were expressed as the number of HPA-positive cells per $10 \mathrm{VCU}$.

\section{Measurement of intestinal mucin}

The procedure described by Khan et al. (1995) was followed for the measurement of intestinal mucin. The upper half of the small intestine was removed and divided into 2 pieces, and each piece was washed carefully with $10 \mathrm{ml}$ of $1 \%$ sodium dodecyl sulfate (SDS) (Sigma). The solution containing mucus was sonicated for $1 \mathrm{~min}$ by an ultrasonicater (American Instrument Exchange, Farmingdale, New York), with maximum output, and then centrifuged at $500 \mathrm{~g}$ for $30 \mathrm{~min}$ at $4 \mathrm{C}$. The supernatant was collected and frozen until used. The amount of mucus was measured as the concentration $(\mathrm{mg} / \mathrm{ml})$ of saccharides using the phenol-sulphuric acid method (Dubois et al., 1956). Briefly, $1 \mathrm{ml}$ of supernatant was mixed with $1 \mathrm{ml}$ of $5 \%$ phenol, and $5 \mathrm{ml}$ of sulphuric acid was added to the mix. The mixture was kept at room temperature for $30 \mathrm{~min}$ and its absorbance was measured at $480 \mathrm{~nm}$.

\section{Semi-quantitative reverse transcriptase RT-PCR for cytokine mRNA}

The MLNs from infected or uninfected control mice were removed and suspended in $0.5 \mathrm{ml}$ TRIzol reagent (Gibco BRL). Total RNA was isolated following a protocol based on the single-step acid guanidinium thiocyanate-phenol-chloroform RNA isolation method. Reverse transcription for the first strand DNA was performed using the SuperScript ${ }^{(10}$ First-strand Synthesis system for RT-PCR (Gibco BRL) according to the manufacturer's instructions. The primer sequences for all genes were taken from previous reports (Svetic et al., 1991; Wynn et al., 1993). Hypoxanthin-guanine phosphoribosyl transferase (HPRT), a primer for housekeeping genes, was used to amplify the cDNA, which was reverse-transcribed from the total RNA to verify amounts of RNA content in each PCR reaction.

A ready-to-use PCR reaction mixture (Bioneer, Daejon, Republic of Korea) was used, and $1 \mu \mathrm{l}$ of cDNA and $10 \mathrm{pmol}$ of each primer set were added to reaction tubes. Distilled water was added to make a final volume of $20 \mu \mathrm{l}$. After an initial incubation at $95 \mathrm{C}$ for $3 \mathrm{~min}$, temperature cycling was initiated as follows: $94 \mathrm{C}$ for $1 \mathrm{~min}, 54-63 \mathrm{C}$ for 1 $\mathrm{min}, 72 \mathrm{C}$ for $2 \mathrm{~min}$, and final extension at $72 \mathrm{C}$ for $7 \mathrm{~min}$. Positive and negative controls were included in each assay to confirm that only cDNA PCR products were detected and that no reagents were contaminated with cDNA or previous PCR products. We selected target cytokines primarily associated with the acute inflammatory response or associated with T-cell activation and proliferation. The number of PCR cycles selected for each cytokine has been reported as follows (Svetic et al., 1991; Wynn et al., 1993): IL-1 $\alpha$ (27 cycles), IL-1 $\beta$ (27 cycles), IL-2 (35 cycles), IL-4 (33 cycles), IL-5 (32 cycles), IL-13 (33 cycles), IFN- $\gamma$ ( 29 cycles), TNF- $\alpha$ ( 32 cycles), and HPRT ( 23 cycles).

Amplified PCR products were electrophoresed in a $2 \%$ agarose gel stained with ethidium bromide and photographed under ultraviolet light. The band density on photographs was analyzed with the densitometrical analysis program, TINA (Raytest, Straubenhardt, Germany). The optical densities of bands were normalized by compensation with the amplified product of HPRT, and the quantity of naive mRNA was deduced. The densitometer unit of each cytokine was expressed as the mean cytokine/ HPRT ratio for 2 PCR samples analyzed individually at each time point. Finally, graphic results were presented as the ratio of infected mice over the uninfected controls.

\section{Statistical analysis}

Data were compared by 1-way analysis of variance and Student's $t$-tests. A $P$-value of $<0.05$ was considered statistically significant.

\section{RESULTS}

\section{Higher resistance of C57BL/6 mice to G. seoi infection than by ICR mice}

The susceptibility of both mouse strains to G. seoi infection was compared. C57BL/6 mice were more resistant to the infection than were ICR mice, and the worm recovery rate (WRR) from C57BL/6 mice was significantly lower $(P<0.05)$ at days 3-7 PI (Fig. 1). ICR mice revealed a slower reduction of worm burdens until day $7 \mathrm{PI}$, and worms were recovered even after day 10 PI. In contrast, C57BL/6 mice showed faster and greater reduction of the worm burden from day 2 PI and, eventually, no worms were recovered at days 4-7 PI. Therefore, we designated ICR mice as slow responders (susceptible strain) and C57BL/6 mice as fast responders (resistant strain). The GC numbers per $10 \mathrm{VCU}$ increased significantly in infected mice $(P<0.05)$ compared with uninfected control mice (day $0 \mathrm{PI}$ ), and this response was closely correlated with worm expulsion 
ICR C57BL/6

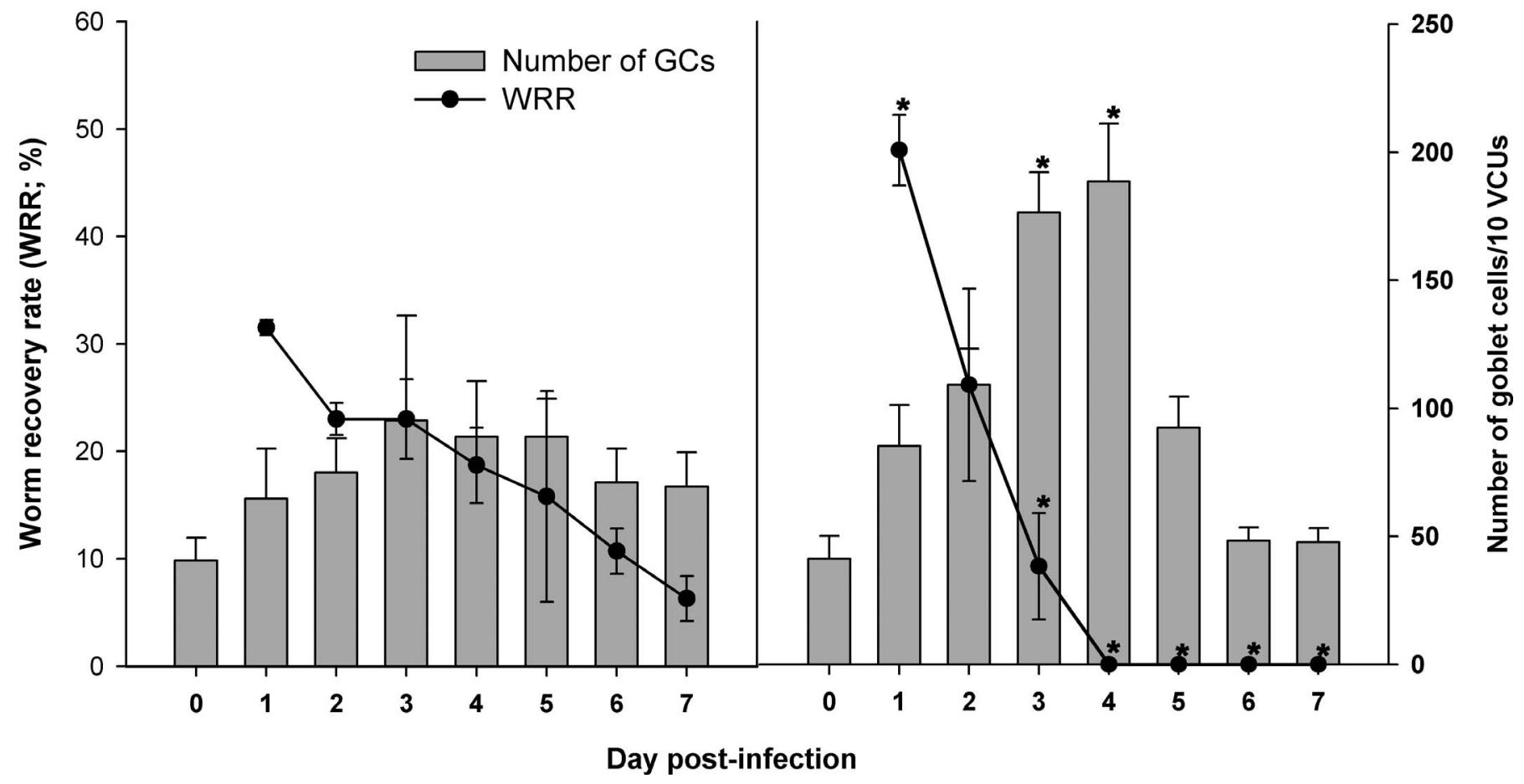

FIGURE 1. Comparison of the worm recovery rate (WRR) of $G$. seoi and the number of goblet cells (GCs) in C57BL/6 and ICR mice infected with 200 metacercariae. C57BL/6 mice showed higher resistance than did ICR mice. The increase in GC number was strongly related with worm expulsion in both strains of mice. GC numbers of all infected mice at days 1-7 PI were significantly higher than in uninfected control mice (day 0 PI $)(P<0.05) . *$ Significantly $(P<0.05)$ higher in C57BL/6 mice than in ICR mice.

(Fig. 1). The GC response of the fast responders was significantly stronger than that of the slow responders at days 3 and 4 PI $(P<0.05)$. The GC number was remarkably reduced in fast responders at worm absence (days 6-7 PI) in the small intestine.

\section{Effects of mucosal CD4+ T-cell transfer on worm expulsion}

Adoptive transfer of mucosal CD4+ T-cells isolated from the infected donor mice was highly effective in worm expulsion from small intestines of naïve C57BL/6 and ICR mice (Fig. 2). The WRR of the $\mathrm{R}_{\text {nor }}$ was not significantly different from that of normal infected (NI) mice. The mean and standard deviation (SD) of WRR in $\mathrm{R}_{\text {nor }}$ was $19.7 \pm 10.7 \%$ in C57BL/6 mice and $26.3 \pm 14.3 \%$ for ICR mice, and the mean and SD of WRR in NI mice was $20.0 \pm 2.3 \%$ in C57BL/6 mice and $26.9 \pm 3.9 \%$ in ICR mice, all at day 2 PI. However, in C57BL/6 mice, the WRR of the $\mathrm{R}_{\mathrm{d} 2 \mathrm{~d}}$ group decreased significantly $(P<0.05)$ throughout days 1,2 , and 3 PI compared with the WWR in the NI group. This decrease in the $\mathrm{R}_{\mathrm{d} 2 \mathrm{~d}}$ group was more pronounced than in the $\mathrm{R}_{\mathrm{d} 7 \mathrm{~d}}$ group mice. Therefore, mucosal CD4+ T-cells of mice at day 2 PI with $G$. seoi were highly effective in enhancing the worm expulsion in the early stages of infection. The worm reduction of $\mathrm{R}_{\mathrm{d} 2 \mathrm{~d}}$ at days 1 and 2 PI were $84.4 \%$ and $91.5 \%$, respectively (Fig. 2). Conversely, in ICR mice, the WRR of the $\mathrm{R}_{\mathrm{d} 7 \mathrm{~d}}$ group was more significantly decreased $(P<$ 0.05) than in the $\mathrm{R}_{\mathrm{d} 2 \mathrm{~d}}$ group, suggesting that $\mathrm{CD} 4+\mathrm{T}$-cells from day 7 PI were more potent in worm expulsion than those from day 2 PI. The worm reduction of $\mathrm{R}_{\mathrm{d} 7 \mathrm{~d}}$ at days 2 PI and 4 PI were $69.2 \%$ and $75.0 \%$, respectively (Fig. 2). The WRRs of $\mathrm{R}_{\mathrm{d} 2 \mathrm{~d}}$ and $\mathrm{R}_{\mathrm{d} 7 \mathrm{~d}}$ groups were both significantly lower than those in the NI group in 2 strains of mice $(P<0.05)$, with the exception of day 7 PI in the ICR mice.

\section{Effects of mucosal CD4+ T-cell transfer on GC hyperplasia}

The mean GC numbers increased significantly $(P<0.05)$ in $G$. seoi-infected mice compared with uninfected mice; C57BL/6 mice had 41.2 $\pm 8.9 \mathrm{GCs}$ per $10 \mathrm{VCU}$ and ICR mice had $41.0 \pm 8.8 \mathrm{GCs}$ per $10 \mathrm{VCU}$. The GC responses in recipient mice were significantly higher than those in NI mice $(P<0.05)$ (Fig. 2). GC numbers in both $R_{\mathrm{d} 2 \mathrm{~d}}$ and $\mathrm{R}_{\mathrm{d} 7 \mathrm{~d}}$ groups were remarkably higher than those in NI mice from day $1 \mathrm{PI}$ in C57BL/6 mice $(P<0.05)$, and the differences between the $\mathrm{R}_{\mathrm{d} 2 \mathrm{~d}}$ and $\mathrm{R}_{\mathrm{d} 7 \mathrm{~d}}$ groups were insignificant (Figs. 2, 4). GC responses in ICR mice were significantly higher in the $\mathrm{R}_{\mathrm{d} 2 \mathrm{~d}}$ and $\mathrm{R}_{\mathrm{d} 7 \mathrm{~d}}$ group mice than in NI mice at days 2 PI and 4 PI $(P<0.05)$ (Fig. 2). However, differences between $R_{d 2 d}$ and $R_{d 7 d}$ mice were insignificant. Worm expulsion actively occurred from day 7 PI, and GC numbers decreased from this point on.

\section{Effects of mucosal CD4- T-cell transfer on GC responses and worm expulsion}

The importance of CD4- T-cells on G. seoi worm expulsion was assessed through observation of the WRR and GC respons- 

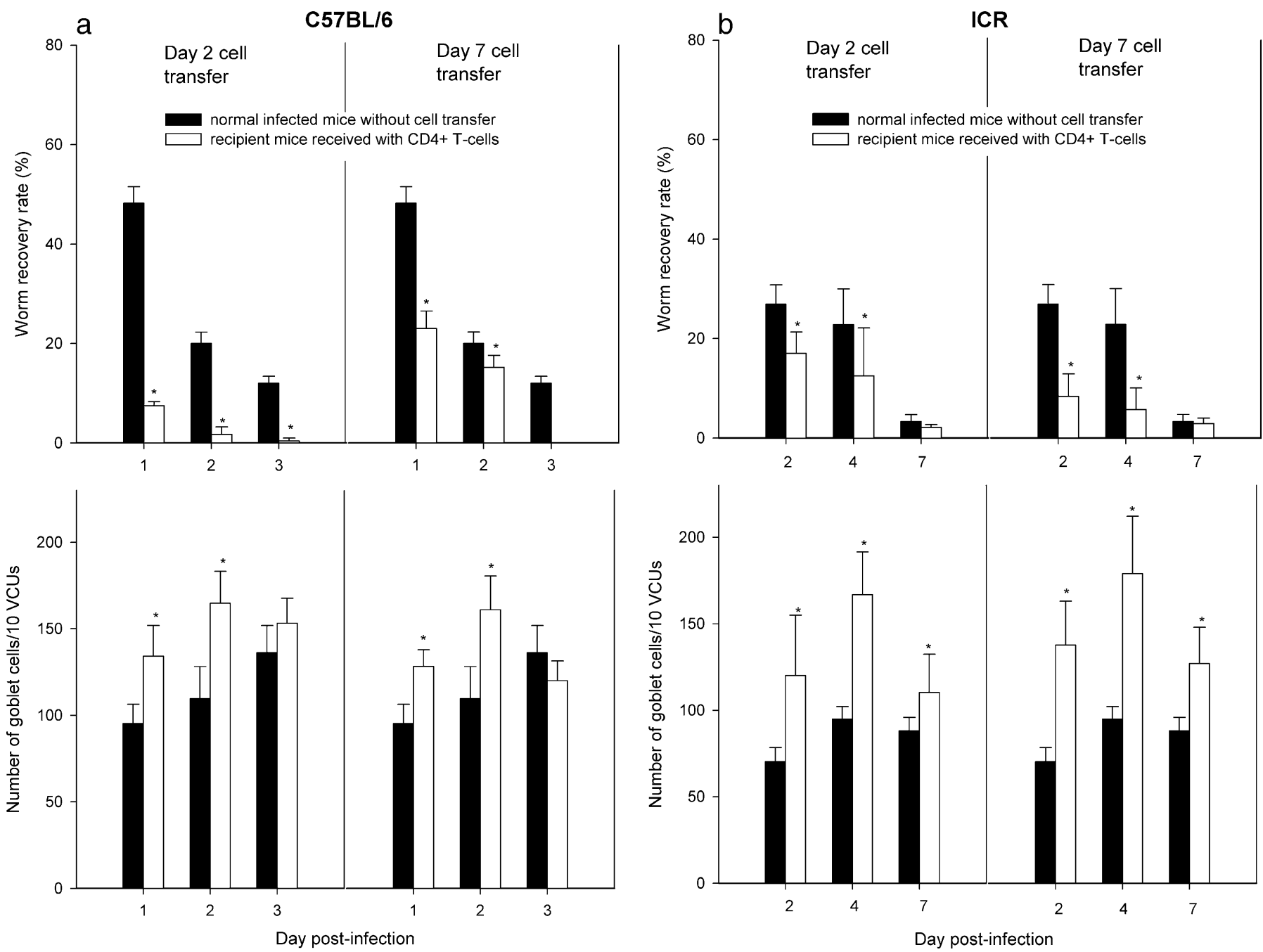

FIGURE 2. Comparison of WRR of $G$. seoi and GC numbers after adoptive transfer of mucosal CD4+ T-cells in C57BL/6 and ICR mice. CD4+ T-cells on day 2 PI were more effective in enhancing GC responses and worm expulsion. *Significantly $(P<0.05)$ lower $($ WRR) or higher (GC numbers) in cell-recipient mice than in non-recipient mice.

es in recipient C57BL/6 mice adoptively transferred with mucosal CD4- T-cells. The WRR and GC responses of recipient mice with CD4- T-cells at day 2 PI were not significantly different from those of NI mice $(P>0.05)$. The mean WRR was $19.7 \pm 7.8 \%$ in NI mice and $24.6 \pm 12.0 \%$ in CD4T-cell-recipient mice, and mean mucosal GC numbers were $109.6 \pm 5.8$ per $10 \mathrm{VCU}$ in NI mice and $109.0 \pm 12.7$ per 10 VCU in CD4- T-cell-recipient mice (Fig. 3). By comparison, the WRR and GC numbers in recipient mice transferred with CD4+ T-cells were significantly lower (WRR) or higher (GC numbers) than in CD4- T-cell-recipient mice $(P<0.05)$.

\section{CD4+ T-cell-independent alteration of terminal sugar chain of mucus}

The mean and SD of HPA-positive GCs per $10 \mathrm{VCU}$ of C57BL/6 mice was $18.5 \pm 10.6$ in uninfected controls, and it was significantly $(P<0.05)$ higher in NI $(58.0 \pm 2.8), \mathrm{R}_{\mathrm{d} 2 \mathrm{~d}}$ $(61.3 \pm 6.8)$, and $R_{d 7 d}$ mice $(62.5 \pm 6.4)$ at day 2 PI by lectin histochemistry (Fig. 4). However, no significant differences were noted among NI, $\mathrm{R}_{\mathrm{d} 2 \mathrm{~d}}$, and $\mathrm{R}_{\mathrm{d} 7 \mathrm{~d}}$ mice $(P>0.05)$. There- fore, alteration of the terminal sugar of mucins in mucosal GCs was independent of CD4+ T-cells in G. seoi infection.

\section{Amount of intestinal mucus in relation to worm expulsion}

The amount of small-intestinal mucus, as expressed by the concentration $(\mathrm{mg})$ of saccharides per volume of tissue $(\mathrm{ml})$ in uninfected and NI mice, was compared in order to evaluate the quantitative changes of the mucus in relation to worm expulsion. In C57BL/6 mice, the amount of mucus at days 1,2 , and 3 PI was significantly higher compared with uninfected controls at day 0 PI $(P<0.05)$ (Fig. 5). The increase in the mucus amount was also significant $(P<0.05)$ at days 2 PI and 7 PI in ICR mice (Fig. 5).

\section{IL-4 and IL-5 mRNA expressions in relation to worm expulsion}

We analyzed the mRNA expression of several cytokines, including IL- $1 \alpha$, IL-1 $\beta$, IL-2, IL-4, IL-5, IL-13, IFN- $\gamma$, and TNF- $\alpha$. We examined the cytokine effects on MLN cells to 


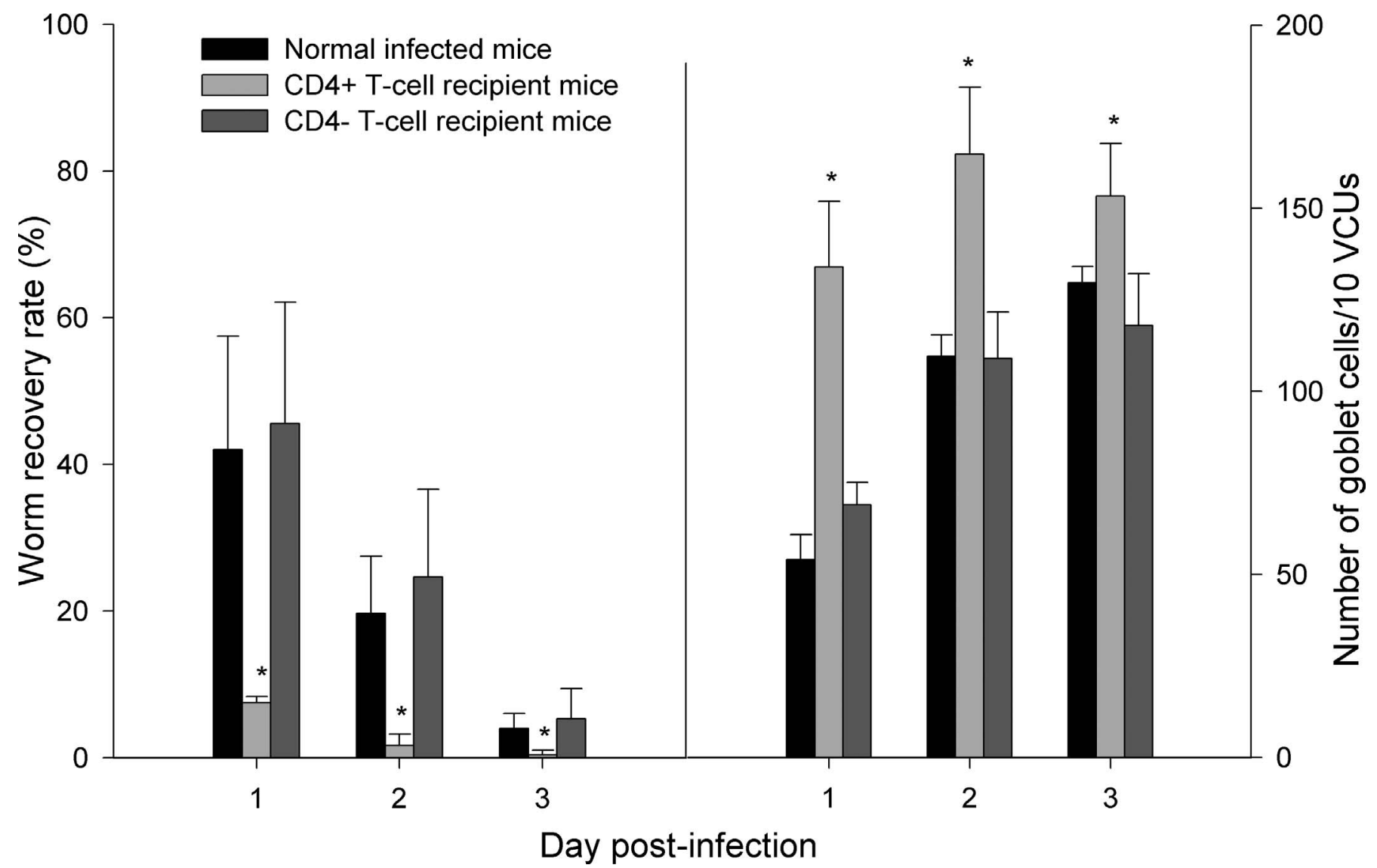

FIGURE 3. Comparisons of WRR and GC responses between CD4+ T-cell-recipient C57BL/6 mice and CD4- T-cell-recipient C57BL/6 mice in the $\mathrm{R}_{\mathrm{d} 2 \mathrm{~d}}$ group. The CD4- T-cell subpopulation was not effective on GC hyperplasia and expulsion of $G$. seoi. *Significantly $(P<0.05)$ lower (WRR) or higher (GC numbers) in CD4+ cell-recipient mice than in NI mice or CD4- T-cell-recipient mice.

ensure whether cytokine levels were related to GC hyperplasia and worm expulsion. The mRNA levels in the resistant C57BL/6 mouse strain of the NI and $\mathrm{R}_{\mathrm{d} 2 \mathrm{~d}}$ groups were assayed on days 1,2 , and 3 PI and compared with the worm-recovery results. The mRNA cytokine levels of infected mice were significantly higher than those of uninfected control mice $(P<$ 0.05), with the exception of IL- $1 \alpha$ and TNF- $\alpha$ (Fig. 6). Strong expressions of cytokine mRNAs were observed in the early phase of infection. In particular, increases in IL-4 and IL-5 were remarkable, and IL-5 was significantly higher in $\mathrm{R}_{\mathrm{d} 2 \mathrm{~d}}$ mice than in NI mice $(P<0.05)$. Pro-inflammatory cytokines such as IL1 group and TNF- $\alpha$ increased by less than 2 -fold, and increases in Th1 cytokines such as IL- 2 and IFN- $\gamma$ were less pronounced than were increases in IL-4 and IL-5 (Fig. 6).

The mRNA levels in ICR mice were assayed in the NI and $\mathrm{R}_{\mathrm{d} 7 \mathrm{~d}}$ groups at days 2, 4, and 7 PI. Levels in ICR mice were generally lower than those in C57BL/6 mice (Fig. 6). With the exception of IL-4 and IL-5, mRNA cytokine levels increased less than 1.0 to 1.5 -fold, and those levels in infected mice were not significantly different from those of uninfected controls (Fig. 6). The mRNA cytokine levels of IL-4 and IL-5 increased more than 1.5-fold at days 2 PI and 4 PI, and the IL-4 mRNA in NI mice was significantly higher than in $\mathrm{R}_{\mathrm{d} 7 \mathrm{~d}}$ group at days 4 PI and 7 PI $(P<0.05)$ (Fig. 6).

\section{DISCUSSION}

The protective immunity of murine hosts against nematode infections is closely related to Th2-type immunity, which is activated by production of Th2 cytokines including IL-4, IL-5, IL-9, and IL-10 (Grencis et al., 1991; Ishikawa et al., 1997). Th1 cytokines, including IL-12, IL-18, and IFN- $\gamma$, inhibit this immunity (Finkelman et al., 1997; Artis et al., 2004). Mice infected with $N$. brasiliensis or $T$. spiralis exhibit Th2type immune responses that are accompanied by marked GC hyperplasia. Mucins secreted from these GCs are important in the trapping and removal of worms from the gut (Ishikawa et al., 1997; Theodoropoulos et al., 2001; Artis et al., 2004). Qualitative changes in the terminal sugar of mucins may play a crucial role in the worm-expulsion process of $N$. brasiliensis (Ishikawa et al., 1993). Immune responses against nematodes can also be mediated by a T-cell-independent mechanism, because GC hyperplasia and mucin production were observed in athymic rats infected with $N$. brasiliensis (Kawai et al., 2007).

Trematode-murine models, such as Echinostoma trivolvis and E. caproni infection, have demonstrated that significant GC hyperplasia was induced close to the time of worm expulsion ( $\mathrm{Fu}-$ jino et al., 1996; Fujino, Ichikawa, and Fried, 1998; Fujino, Ichikawa, Fukuda, and Fried, 1998; Toledo et al., 2006). Hamsters are a susceptible host for E. caproni and have displayed 

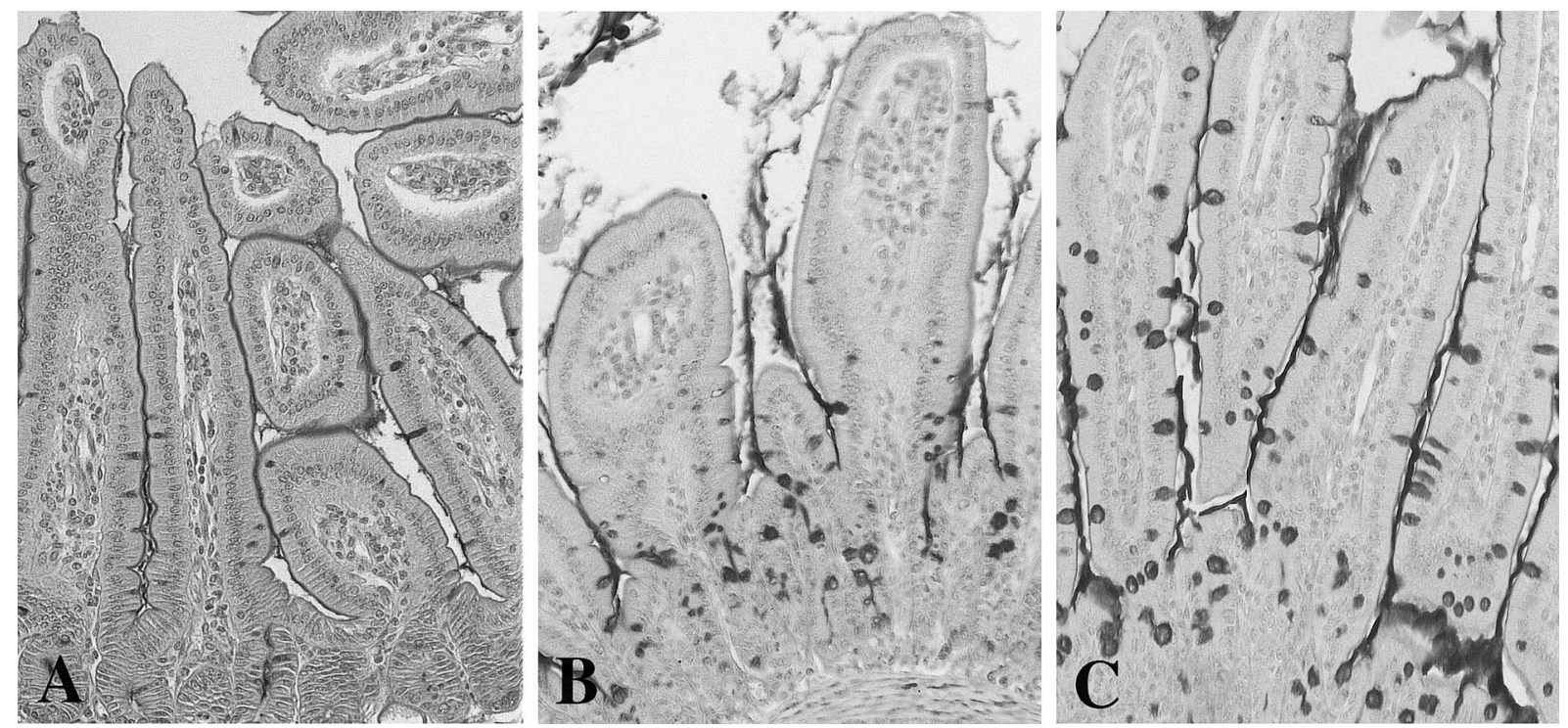

FIGURE 4. Sections of the small intestines of C57BL/6 mice infected with $G$. seoi showing GC proliferation. (A) Uninfected control mice, (B) Normal infected mice at day $2 \mathrm{PI}$; (C) $\mathrm{R}_{\mathrm{d} 2 \mathrm{~d}}$-group recipient mice. Lectin histochemistry was performed to detect altered GC mucins using Helix pomatia agglutinin, which specifically recognizes the terminal GalNAc residues on the altered GC mucins. PAS stain $(\times 200)$.

significantly smaller GC numbers than rats, a resistant host (Toledo et al., 2006). The involvement of GCs in worm expulsion of E. caproni seemed evident (Fujino, Ichikawa, and Fried, 1998). The immune mechanics may be more complex than previously considered because GC hyperplasia was also observed in recombinase activating gene-2 (RAG-2)-deficient mice lacking T- and B-cells (Frazer et al., 1999). These mice failed to reject E. caproni (Frazer et al., 1999). There have been no reports on the observation of alteration of terminal sugar residues on GC mucins in E. caproni and other echinostome models. Establishment of chronic infection with E. caproni in mice is induced by an early Th1 response with elevated levels of INF- $\gamma$ (Brunet et al., 2000). This is different from immune responses in nematode infections in which Th2-type immunity predominates (Theodoropoulos et al., 2001; Artis et al., 2004).

Worm-rejection kinetics were different in $G$. seoi infection depending on the strain of mouse, as $\mathrm{C} 57 \mathrm{BL} / 6$ mice rejected most of the worms during days 2-6 PI, and ICR and C3H/HeN
FigURE 5. Amount of small-intestinal mucus, as expressed by concentration of saccharides per $\mathrm{ml}$ of mucosal tissue, secreted from GCs. In C57BL/6 mice, the mucus amount was significantly $(* P<0.05)$ increased at days 1,2 , and 3 PI compared with uninfected control mice (day 0 PI). In ICR mice, the increase was significant $(* P<0.05)$ at days 2 $\mathrm{PI}$ and 7 PI as compared with uninfected controls (day $0 \mathrm{PI}$ ).
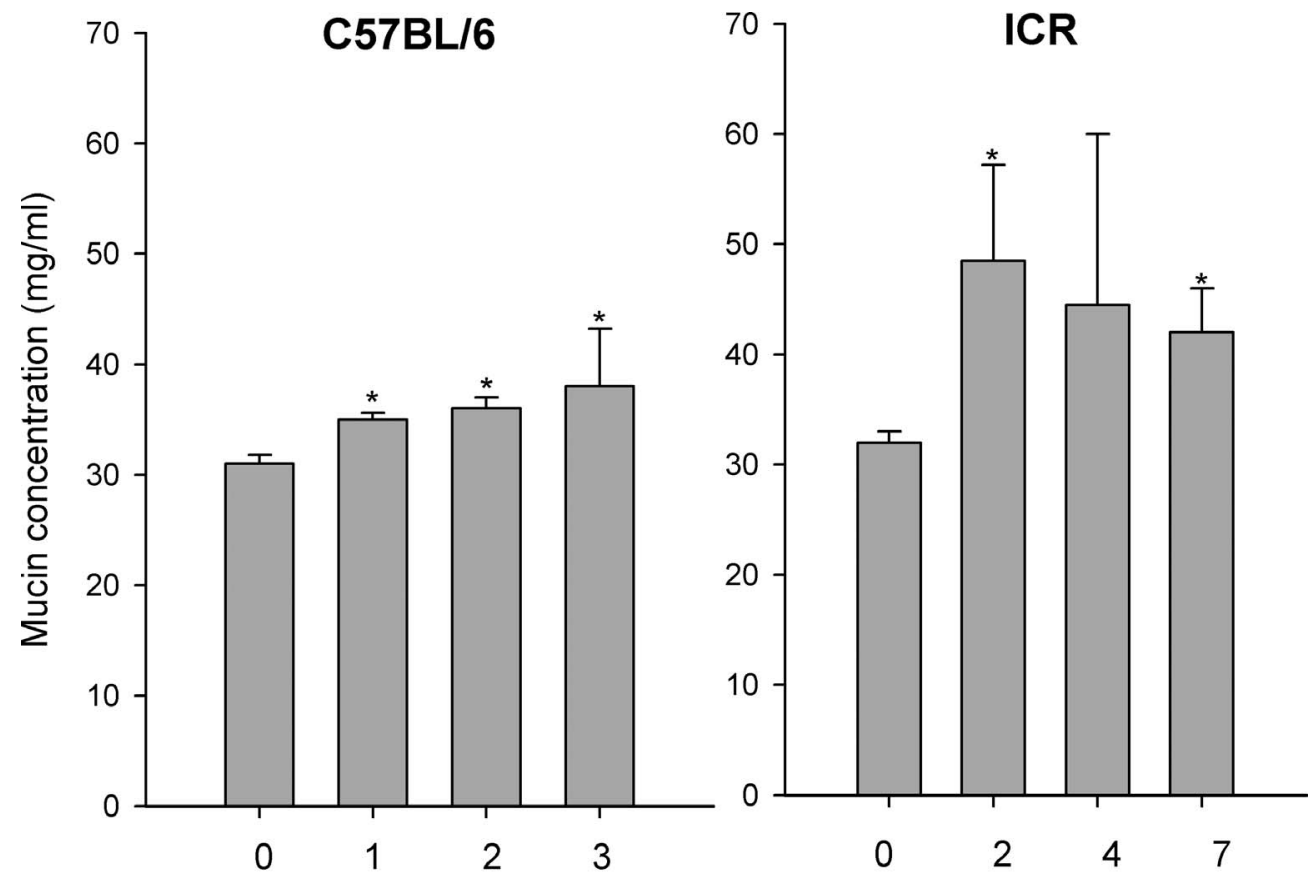

Day post-infection 


\section{C57BL/6 mice}

- Normal infected mice

$\multimap$ Recipient mice received cells of day $2 \mathrm{PI}$

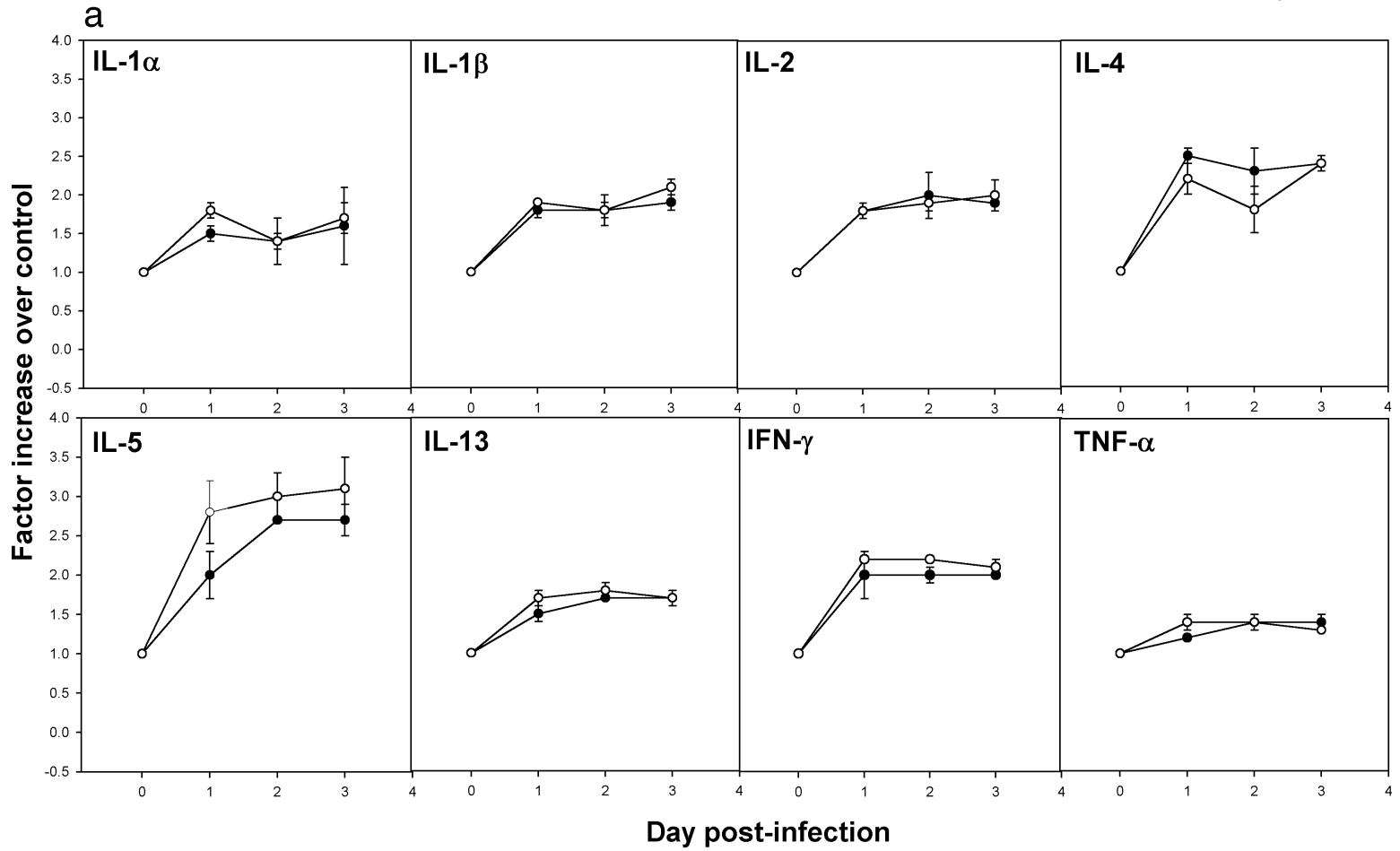

ICR mice

- Normal infected mice

— Recipient mice received cells of day $7 \mathrm{PI}$

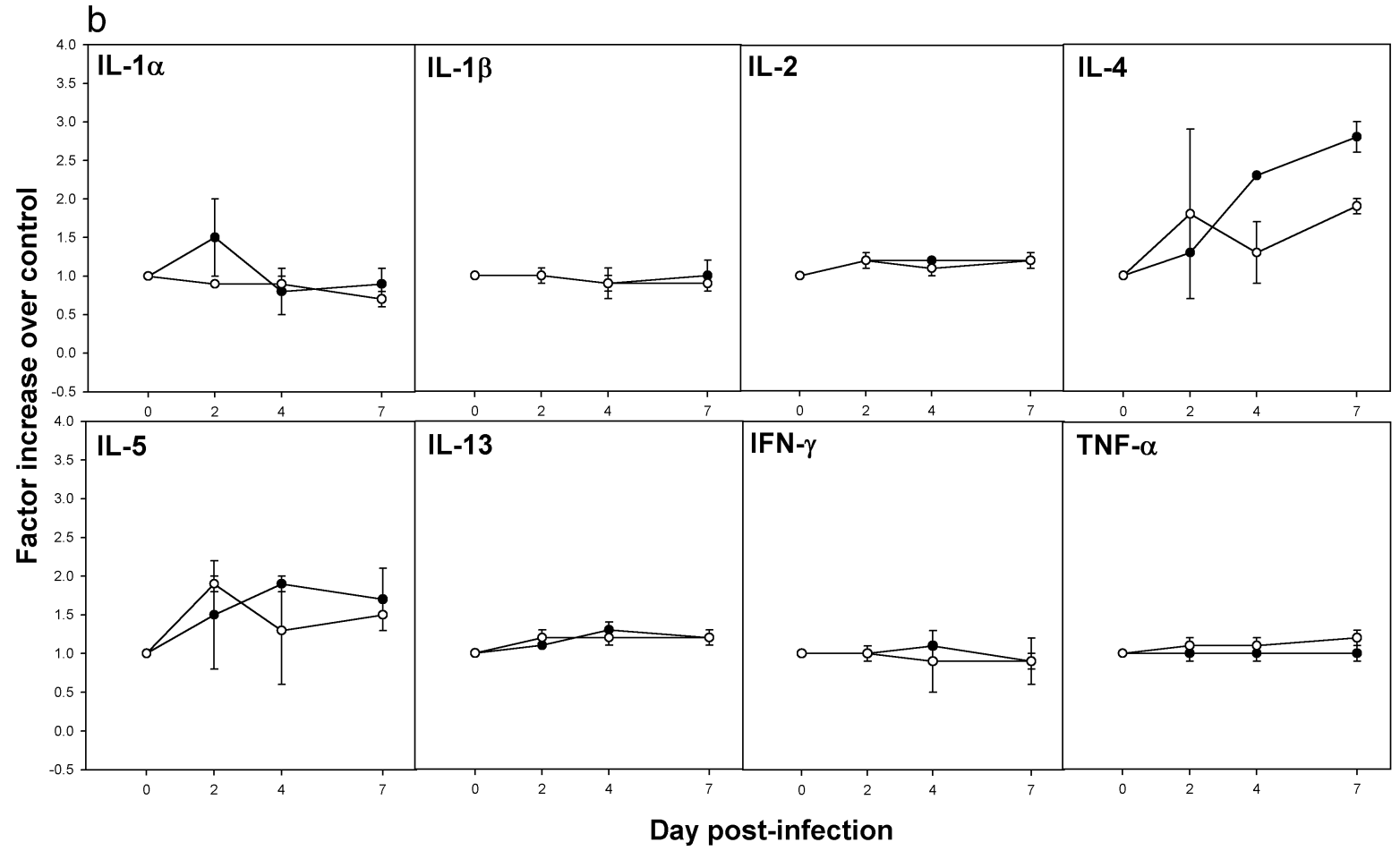

FIGURE 6. Cytokine mRNA expression in C57BL/6 and ICR mice. Values were expressed as the factor increase over controls between uninfected mice and CD4+ T-cell-recipient mice on day 2 PI in C57BL/6 mice $\left(R_{\mathrm{d} 2 \mathrm{~d}}\right)$ or day 7 PI in ICR mice $\left(\mathrm{R}_{\mathrm{d} 7 \mathrm{~d}}\right)$. Values of all types of cytokines were significantly increased $(P<0.05)$ in infected mice rather than in uninfected controls in C57BL/6 mice, with the exception of IL$1 \alpha$ and TNF- $\alpha$. In ICR mice, the values of all types of cytokines were not significantly increased, with the exception of IL-4 and IL-5, which showed more than 1.5-fold increases. In particular, the mRNA of IL-4 in normal infected mice was significantly higher $(P<0.05)$ than that in the $\mathrm{R}_{\mathrm{d} 7 \mathrm{~d}}$ group at days $4 \mathrm{PI}$ and $7 \mathrm{PI}$. 
mice retained most worms until day 8-13 PI (Seo et al., 2003). The degree of GC hyperplasia varied significantly by individual mouse strains, and involvement of GCs in the worm expulsion was suggested (Seo et al., 2003). Our study suggests that GCs are involved in worm rejection of $G$. seoi from mouse intestines. GC proliferation appeared to be CD4+ T-cell dependent, but GC activation in terms of alteration of GC mucins was CD4+ T-cell independent.

Th2 immune responses by MLN cells on day 8 PI with $T$. spiralis were reported in studies investigating the relationship between cytokine quantity in vitro and parasite expulsion (Grencis et al., 1991; Ishikawa et al., 1997). Ishikawa et al. (1997) compared the effects of MLN cell transfer on GC numbers in recipient mice. In $T$. spiralis infection, a transfer of MLN cells obtained from syngeneic mice on day 8 PI significantly enhanced GC hyperplasia in recipient mice, and it was suggested that small intestinal GC hyperplasia in $T$. spiralisinfected animals is regulated by Th2 cells (Ishikawa et al., 1997).

We performed cell-transfer experiments in the present study using different strains of mice. Transfer of MLN-CD4+ T-cells obtained on day 2 PI with G. seoi had significant effects on $\mathrm{GC}$ responses in the resistant recipient mice (C57BL/6). By contrast, the transfer of MLN-CD4+ T-cells obtained on day 7 PI had significant effects on GC responses in the susceptible recipient mice (ICR). There was a difference in the kinetics of $\mathrm{GC}$ responses in association with parasite expulsion between the 2 mouse strains. GC hyperplasia in our studies was typically related to a decrease in the number of worms in the small intestine. Previous studies have shown that host animals became resistant to reinfection with $T$. spiralis after worm expulsion (Wakelin and Wilson, 1979). This immunity could be transferred by T-helper cells, and available data indicate that Th2 cells engage in this transfer (Grencis et al., 1985).

Previous studies using lectin histochemistry suggested that the alteration of terminal sugars of GC mucins was closely associated with expulsion of nematodes (Ishikawa et al., 1993, 1994; Ishikawa, 1994; Khan et al., 1995). Alteration of terminal sugars of GC mucins is indicative of functional activation of GCs (Ishikawa et al., 1993, 1994; Ishikawa, 1994). Changes of GCs during $N$. brasiliensis expulsion can be divided into a T-cell-dependent proliferation and a T-cell-independent alteration of terminal sugars of mucins, and these qualitative changes seem to be more critical for worm expulsion (Nawa et al., 1994). Alteration of terminal sugars of mucins was significantly increased in all infected mice in our study. This response was also significantly greater in the $\mathrm{R}_{\mathrm{d} 2 \mathrm{~d}} \mathrm{C} 57 \mathrm{BL} / 6$ mice than in control mice, but no significant increases were shown in other recipient mice. Alteration of terminal sugars of mucins is important in worm expulsion of G. seoi, and this response could be induced by a T-cell-independent process.

Our study also revealed that the mucin amount in the small intestine was increased by G. seoi infection. In particular, saccharide amounts increased in connection with GC hyperplasia in C57BL/6 mice. The kinetics of intestinal saccharide amounts were well correlated with GC hyperplasia in the small intestine of mice in previous studies (Khan et al., 2001). Therefore, the majority of the increased intestinal saccharides were probably of mucin origin. Further, adoptive transfer with CD4+ T-cells selected from infected donor mice increased the amount of sac- charides in intestines from NI mice (data not shown). It is, therefore, likely that CD4+ T-cell transfer can increase the release of mucins from GCs.

GCs are exocrine cells of the intestinal epithelium and are specialized in mucin exocytosis. After secretion, mucin hydrates to form a viscous gel that forms a major barrier between the intestinal contents and underlying mucosa (Khan et al., 2001). Mucus trapping was considered as a non-specific defense mechanism of the host in the past, but studies have indicated that the protective role of GC mucins in worm expulsion is rather selective (Khan et al., 2001). GC hyperplasia and alteration of terminal sugar residues of GC mucins may be related to selective binding of mucus to the surface of parasite species. Studies are required to elucidate the precise role of altered mucins on $G$. seoi expulsion in C57BL/6 mice.

It was recently reported that Th2 cytokines may regulate GC hyperplasia and protective immunity in the gut during $T$. spiralis infection via the Stat6 (signal transducer and activator of transcription factor 6) signaling pathway (Urban et al., 2000; Khan and Collins, 2004). The interaction between each cytokine and its receptor leads to activation of signaling molecules including Stat proteins; and Stat6, which is essential for Th2 immunity development, is activated by both IL4 and IL-13 (Nelms et al., 1999). A critical role for Stat6 has been reported in allergen-induced airway hyper-responsiveness and mucus production (Kuperman et al., 1998). Stat4 is activated by IL-12 and is important in Th1-type responses (Kuperman et al., 1998).

Cytokine mRNA expression was examined in our study to understand T-cell-derived molecules and their correlation with GC responses and expulsion of G. seoi. The expression levels of cytokines in the resistant C57BL/6 mice were higher than those in the susceptible ICR mice. The expressions of IL-4 and IL-5 were meaningfully increased at the early stages of infection. These cytokines appear to be associated with GC hyperplasia and the expulsion of $G$. seoi. Infection with $T$. spiralis revealed that IL-5 did not act as a Th2-derived factor, and GC hyperplasia was not induced directly in response to a factor produced by Th2 cells, but by secretory products induced by this factor in other cells (Ishikawa et al., 1997). This should be studied in G. seoi infection in C57BL/6 mice. It is further suggested that a Stat signaling pathway, by stimulation or activation of IL-4 and IL-5, may be involved in the GC hyperplasia and worm expulsion in mice infected with $G$. seoi.

In summary, C57BL/6 mice can expel G. seoi worms more quickly than ICR mice. The GC hyperplasia in the small intestine of $G$. seoi-infected mice was regulated by CD4+ T-cells, although the alteration of the terminal sugar chain of mucins is probably induced by a non-CD4 $+\mathrm{T}$-cell-dependent process. Adoptive transfer of mucosal CD4+ cells, but not CD4- cells, was effective in regulating GC responses and facilitated worm expulsion from the 2 strains of mice. Qualitative changes in the GC mucins were more important than quantitative increases in GCs for worm expulsion. The mRNA expression of Th2 cytokines, particularly IL-4 and IL-5, was positively correlated with worm expulsion during the early stage of infection.

\section{ACKNOWLEDGMENTS}

We thank Jae-Lip Kim (Department of Parasitology and Tropical Medicine, Seoul National University College of Medicine) for his tech- 
nical assistance. This work was supported by a grant from the Seoul National University College of Medicine Research Fund (2004).

\section{LITERATURE CITED}

Artis, D., M. L. W. Wang, S. A. Keilbaugh, W. He, M. Brenes, G. P. Swain, P. A. Knight, D. D. Donaldson, M. A. Lazar, H. R. P. MiLLER ET AL. 2004. RELM $\beta /$ FIZZ2 is a goblet cell-specific immune-effector molecule in the gastrointestinal tract. Proceedings of the National Academy of Sciences USA 101: 13596-13600.

Beaver, P. C., J. C. Jung, AND E. W. CupP. 1984. Clinical parasitology, 9th ed. Lea and Febiger, Philadelphia, Pennsylvania, 755 p.

Brunet, L. R., S. Joseph, D. W. DunNe, And B. Fried. 2000. Immune responses during the acute stages of infection with the intestinal trematode Echinostoma caproni. Parasitology 120: 565-571.

Chai, J. Y., M. H. Chol, J. R. Yu, AND S. H. Lee. 2003. Gymnophalloides seoi, a new human intestinal trematode. Trends in Parasitology 19: 109-112.

, T. K. Kim, W. H. Cho, M. Seo, J. Kook, S. M. GuK, and S. H. LEE. 1998. Intestinal mastocytosis and goblet cell hyperplasia in $\mathrm{BALB} / \mathrm{c}$ and $\mathrm{C} 3 \mathrm{H}$ mice infected with Neodiplostomum seoulense. Korean Journal of Parasitology 36: 109-119.

Cho, Y. K., Y. S. Ryang, I. S. Kim, S. K. PARK, J. A. Im, AND K. J. LEE. 2007. Differential immune profiles following experimental Echinostoma hortense infection in $\mathrm{BALB} / \mathrm{c}$ and $\mathrm{C} 3 \mathrm{H} / \mathrm{HeN}$ mice. Parasitology Research 100: 1053-1061.

Dehlawi, M. S., Y. R. Mahida, K. Hughes, and D. Wakelin. 2006. Effect of Trichinella spiralis infection on intestinal pathology in mice lacking interleukin-4 (IL-4) or intestinal trefoil factor (ITF/ TFF3). Parasitology International 55: 207-211.

Dubois, M., K. A. Gilles, J. K. Hamilton, P. A. Rebers, and F. Smith. 1956. Colorimetric method for determination of sugar and related substances. Analytical Chemistry 28: 350-356.

ElSE, K. J., AND F. D. FinKelman. 1998. Intestinal nematode parasites, cytokines and effector mechanisms. International Journal for Parasitology 28: 1145-1158.

Finkelman, F. D., T. Shea-Donahue, J. Goldhill, C. A. Sullivan, S. C. Morris, K. B. Madden, W. C. Gause, and J. F. Urban. 1997. Cytokine regulation of host-defense against parasitic gastrointestinal nematodes, lessons from studies with rodent models. Annual Review of Immunology 15: 505-533.

Frazer, B. A., B. Fried, T. Fujino, And B. P. Sleckman. 1999. Hostparasite relationships between Echinostoma caproni and RAG-2deficient mice. Parasitology Research 85: 337-342.

FujINO, T., B. Fried, H. ICHIKAWA, AND I. TADA. 1996. Rapid expulsion of the intestinal trematodes Echisnostoma trivolvis and E. caproni from $\mathrm{C} 3 \mathrm{H}$ mice by trapping with increased goblet cell mucins. International Journal for Parasitology 26: 319-324.

-, H. ICHIKAWA, AND B. FRIED. 1998. The immunosuppressive compound FK506 does not affect expulsion of Echinostoma trivolvis in $\mathrm{C} 3 \mathrm{H}$ mice. Parasitology Research 84: 519-521.

K. FuKUdA, AND B. FRIED. 1998. The expulsion of Echinostoma trivolvis caused by goblet cell hyperplasia in severe combined immunideficient (SCID) mice. Parasite 5: 219-222.

Grencis, R. K., L. Hultner, AND K. J. Else. 1991. Host protective immunity to Trichinella spiralis in mice, activation of Th cell subsets and lymphokine secretion in mice expressing different response phenotypes. Immunology 74: 329-332.

, J. Riedlinger, AND D. WAKELIN. 1985. L3T4-positive T lymphoblasts are responsible for transfer of immunity to Trichinella spiralis in mice. Immunology 56: 213-218.

Guk, S. M., J. Y. Park, M. Seo, E. T. Han, J. L. Kim, and J. Y. Chai. 2005. Susceptibility of inbred mouse strains to infection with three species of Metagonimus prevalent in the Republic of Korea. Journal of Parasitology 91: 12-16.

Humphreys, N. E., D. Xu, M. R. Hepworth, F. Y. Liew, and R. K. GRENCIS. 2008. IL-3, a potent inducer of adaptive immunity to intestinal nematodes. Journal of Immunology 180: 2443-2449.

IsHIKAWA, N. 1994. Histochemical characteristic of the goblet cell mucins and their role in defense mechanisms against Nippostrongylus brasiliensis infection in the small intestine of mice. Parasite Immunology 16: 649-654. the terminal sugars of goblet cell mucins in the small intestine of Nippostrongylus brasiliensis-infected rats. Immunology 78: 303 307.

, T. Oinuma, T. Suganuma, and Y. Nawa. 1994. Goblet cell mucins as the selective barrier for the intestinal helminthes, T-cell-independent alteration of goblet cell mucins by immunologically 'damaged' Nippostrongylus brasiliensis worms and its significance on the challenge infection with homologous and heterologous parasites. Immunology 81: 480-486.

, D. WAKELIN, AND Y. R. MAHIDA. 1997. Role of T helper 2 cells in intestinal goblet cell hyperplasia in mice infected with Trichinella spiralis. Gastroenterology 113: 542-549.

Kawai, Y., J. Yamauchi, K. Soga, M. Yamada, R. UchiKawa, T. TeGOSHI, AND N. ARIZONO. 2007. T cell-dependent and -independent expression of intestinal epithelial cell-related molecules in rats infected with the nematode Nippostrongylus brasiliensis. Acta Pathologica Microbiologica et Immunologica Scandinaviaca (APMIS) 115: $210-217$.

Khan, W. I., T. Abe, N. Ishikawa, Y. Nawa, And K. Yoshimura. 1995. Reduced amount of intestinal mucus by treatment with anti-CD4 antibody interferes with the spontaneous cure of Nippostrongylus brasiliensis-infected in mice. Parasite Immunology 17: 485-491.

, P. Blennerhasset, C. Ma, K. I. Matthaei, and S. M. Collins. 2001. Stat6 dependent goblet cell hyperplasia during intestinal nematode infection. Parasite Immunology 23: 39-42.

, AND S. M. Collins. 2004. Immune-mediated alteration in gut physiology and its role in host defense in nematode infection. Parasite Immunology 26: 319-326.

Kringel, H., T. Iburg, H. Dawson, B. Aasted, and A. RoepstorfF. 2006. A time course study of immunological responses in Trichuris suis infected pigs demonstrates induction of a local type 2 response associated with worm burden. International Journal for Parasitology 36: $915-924$

Kuperman, D., B. Schofield, M. Wills-Karp, AND M. J. GRusby. 1998. Signal transducer and activator of transcription factor 6 (Stat6)deficient mice are protected from antigen-induced airway hyperesponsiveness and mucus production. Journal of Experimental Medicine 187: 939-948.

LeE, S. H., AND J. Y. Chai. 2001. A review of Gymnophalloides seoi (Digenea, Gymnophallidae) and human infections in the Republic of Korea. Korean Journal of Parasitology 39: 85-118.

, H. J. Lee, S. T. Hong, J. R. Yu, W. M. Sohn, W. G. KHо, M. H. ChOI, AND Y. J. LiM. 1994. High prevalence of Gymnophalloides seoi infection in a village on a southwestern island of the Republic of Korea. American Journal of Tropical Medicine and Hygiene 51: 281-285

, S. K. Park, M. Seo, S. M. GuK, M. H. Choi, and J. Y. Chai. 1997. Susceptibility of various species of animals and strains of mice to Gymnophalloides seoi infection and the effects of immunosuppression in $\mathrm{C} 3 \mathrm{H} / \mathrm{HeN}$ mice. Journal of Parasitology 83: 883886.

Nawa, Y., N. Ishikawa, K. Tsuchiya, Y. Horit, T. Abe, A. I. Khan, B. Shi, H. ITOH, H. IDE, AND F. UChiyama. 1994. Selective effector mechanisms for the expulsion of intestinal helminths. Parasite Immunology 16: 333-338.

Nelms, K., A. D. Keegan, J. Zamorano, J. J. Ryan, and W. E. Paul. 1999. The IL-4 receptor, signaling mechanisms and biological functions. Annual Review of Immunology 17: 701-738.

ONAH, D. N., AND Y. NAwA. 2000. Mucosal immunity against parasitic gastrointestinal nematodes. Korean Journal of Parasitology 38: 209-236.

Seo, M., S. M. GuK, E. T. HAN, AND J. Y. Chai. 2003. Role of intestinal goblet cells in the expulsion of Gymnophalloides seoi from mice. Journal of Parasitology 89: 1080-1082.

Shin, E. H., S. M. Guk, H. J. Kim, S. H. Lee, and J. Y. Chai. 2008. Trends in parasitic diseases in the Republic of Korea. Trends in Parasitology 24: 143-150.

Svetic, A., F. D. Finkelman, Y. C. Jian, C. W. Dieffenbach, D. E. Scott, K. F. McCarthy, A. D. Steinberg, and W. C. Gause. 1991 Cytokine gene expression after in vitro primary immunization with goat antibody to mouse IgD antibody. Journal of Immunology 147: 2391-2397.

Theodoropoulos, G., S. J. Hicks, A. P. Corfiels, B. G. Miller, And 
S. D. CARrington. 2001. The role of mucin in host-parasite interactions: Part II-helminth parasites. Trends in Parasitology 17: 130135.

Toledo, R., C. Monteagudo, A. Espert, B. Fried, J. G. Esteban, and A. MARCILLA. 2006. Echinostoma caproni: Intestinal pathology in the golden hamster, a highly compatible host, and the Wistar rat, a less compatible host. Experimental Parasitology 112: 164-171.

Urban, J. F., L. Schopf, S. C. Morris, T. Orekhova, K. B. Madden, C. J. Betts, H. R. Gamble, C. Byrd, D. Donaldson, K. Else et AL. 2000. Stat6 signaling promotes protective immunity against Trichinella spiralis through a mast cell and $\mathrm{T}$ cell dependent mechanism. Journal of Immunology 164: 2046-2052.
Wakelin, D., AND M. M. Wilson. 1979. T and B cells in the transfer of immunity against Trichinella spiralis in mice. Immunology 37: 103-109.

Webb, R. A., T. Hoque, And S. Dimas. 2007. Expulsion of the gastrointestinal cestode, Hymenolepis diminuta by tolerant rats: Evidence for mediation by a Th2-type immune enhanced goblet cell hyperplasia, increased mucin production and secretion. Parasite Immunology 29: 11-21.

Wynn, T. A., I. Eltoum, A. W. Cheever, F. A. Lewis, W. C. Gause, AND A. SHER. 1993. Analysis of cytokine mRNA expression during primary granuloma formation induced by eggs of Schistosoma mansoni. Journal of Immunology 151: 1430-1440. 